\title{
IVF, same-sex couples and the value of biological ties
}

\author{
Ezio Di Nucci
}

\section{Correspondence to}

Dr Ezio Di Nucci, University of Copenhagen, Copenhagen, Denmark; ezio@sund.ku.dk

Received 16 November 2015 Revised 8 June 2016 Accepted 11 August 2016 Published Online First 9 September 2016

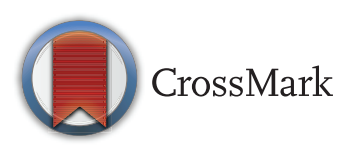

To cite: Di Nucci E. J Med Ethics 2016;42:784-787.

\section{ABSTRACT}

Ought parents, in general, to value being biologically tied to their children? Is it important, in particular, that both parents be biologically tied to their children? I will address these fundamental questions by looking at a fairly new practice within IVF treatments, so-called IVFwith-ROPA (Reception of Oocytes from Partner), which allows lesbian couples to 'share motherhood', with one partner providing the eggs while the other becomes pregnant. I believe that IVF-with-ROPA is, just like other IVF treatments, morally permissible, but here I argue that the increased biological ties which IVF-with-ROPA allows for do not have any particular value beside the satisfaction of a legitimate wish, because there is no intrinsic value in a biological tie between parents and children; further, I argue that equality within parental projects cannot be achieved by redistributing biological ties.

Ought parents, in general, to value being biologically tied to their children? Is it important, in particular, that both parents be biologically tied to their children? I will address these fundamental questions by looking at a fairly new practice within IVF treatments, so-called IVF-with-ROPA (Reception of Oocytes from Partner), ${ }^{1}$ which allows lesbian couples to 'share motherhood', with one partner providing the eggs while the other becomes pregnant. ${ }^{2-5}$ I believe that IVF-with-ROPA is, just like other IVF treatments, morally permissible (for an ethical defence of IVF-with-ROPA, which I will just assume, see refs 2 and 5), but here I argue that the increased biological ties which IVF-with-ROPA allows for do not have any particular value besides the satisfaction of a legitimate wish, because there is no intrinsic value in a biological tie between parents and children; further, I argue that equality within parental projects cannot be achieved by redistributing biological ties.

\section{ROPA: RECEPTION OF OOCYTES FROM PARTNER}

There are different reasons why a couple may want IVF-with-ROPA (I mean the following list to be representative of the diversity in circumstances and motivation rather than exhaustive):

a. There may be some medical grounds which either prevents the donating partner from becoming pregnant or makes it advisable that she not become pregnant;

b. There may be some medical grounds which either prevents the receiving partner from using her eggs or makes it advisable that she not do so-for example a known higher genetic risk;

c. There may be non-strictly-medical reasons why the donating partner does not wish to become pregnant, such as trauma related to previous successful or unsuccessful pregnancies (if those issues affect the mental health of the donating partner, then this consideration will belong in group (a));

d. A predicted lower success rate in case the eggs of the receiving partner are used (again, here it may be argued that this kind of consideration really belongs to (b));

e. Both partners may want to be biological parents of the child (it is standard in the literature to refer to both genetic parenthood and gestational parenthood as biological parenthood; ${ }^{5}$ I am going to follow that convention);

(e1) the above wish may have to do with their future parental relations with their child or anyhow with the welfare of the future child;

(e2) or it may have to do with their own relationship, so that they may not value a biological connection to the child per se but they may value not creating a possible imbalance in the relationship due to only one partner having a biological relationship to the child. Note that it is not necessarily unreasonable not to value biological parenthood while at the same time fearing that an asymmetry in biological parenthood may have consequences for the relationship, since reasons for the latter may have to do with factors external to the partners such as, say, prejudice or peer-pressure. There is in fact some evidence that both equality and jealousy are concerns ${ }^{6}{ }^{7}$-and I think this may be relevant for both (e1) and (e2);

f. The couple may have a non-medical reason (say a reason of aesthetic taste) for not wanting to use the receiving partner's eggs. This may be either an absolute consideration or one which is only relative to the donating partner's eggs; ${ }^{\text {ii }}$

g. There may be non-medical reasons why the donating partner does not wish to become pregnant (just think of the non-medical reasons why someone may opt for surrogacy). ${ }^{\text {iii }}$

${ }^{\mathrm{i}}$ Age is another possible reason which may be medical but does not need to be-thanks to a referee for the suggestion.

${ }^{\mathrm{ii}}$ This last point is important because it makes a difference in terms of which alternatives to IVF-with-ROPA may be available given the particular preferences.

iii Of course in real life a couple's motivation for wanting IVF-with-ROPA will be more like a mix of the above considerations, including the partners having different reasons or weighing their reasons differently; the real-life case illustrated in ref. 5 does a good job of showing these kinds of added complications. Also, see refs. 8 and 9 for how social gender may be a reason for not wanting to become pregnant in lesbian couples-again thanks to a referee for this suggestion. 
When considering these different motivations for wanting IVF-with-ROPA, we must keep in mind that there will be different alternatives depending on the particular circumstances. For example, surrogacy would be a viable alternative in the case of (a), (c) and (g), while non-ROPA-IVF or just IUI (intrauterine insemination) may be a viable alternative to (b), (d) and (f). ${ }^{\text {iv }}$ Further, adoption will be an alternative in all of these cases (even though some of these alternatives may not be desired, eg, because of the wish to become a biological parent in the case of adoption).

Looking at the different circumstances which may lead to IVF-with-ROPA, I can see two extremes: on the one hand, there may be a very difficult medical situation of partner Anne not being able to provide her eggs while partner Beth is not able to become pregnant, which would leave just enough room for IVF-with-ROPA, even though that would not be the only alternative (egg donation would be an alternative, with Anne gestating; also, surrogacy would be an alternative, with Beth's eggs; adoption would also be an option).

At the other end of the spectrum we could have the following case: there are no medical issues with either Carol or Denise, neither in terms of their capacity to become genetic parents nor with their capacity to become gestational parents; still, Carol has some physical trait such that the couple, for aesthetic reasons, does not want to run the risk of that trait being passed on to their offspring, while Denise (or the couple) fears the wage loss related to her gestation. Again, IVF-with-ROPA would just do the job in this case too, while, again, the same alternatives available for Anne and Beth would also be open to Carol and Denise.

The difference between surrogacy, egg donation and adoption on the one hand and IVF-with-ROPA on the other hand is exactly that only IVF-with-ROPA offers the possibility of a biological connection to both parents (at least in the context of same-sex relationships). ${ }^{\mathrm{v}}$ There is also something that all of these practices have in common: there will always be some other biological connection external to the parental project, whether one goes for surrogacy (one gestational relationship external to the parental project), egg donation (two genetic relationships external to the parental project), adoption (normally but not necessarily, one genetic and one genetic/gestational relationship external to the parental project) or IVF-with-ROPA (one genetic relationship external to the parental project).

The two sets of somewhat extreme circumstances I have illustrated point to a significant divide within IVF-with-ROPA: namely that there can be either medical reasons (in a broad sense meant to also include most cases of (c) and (d)) to request this particular treatment or non-medical reasons to request IVF-with-ROPA. Within this broad divide, I would include the wish to have a biological connection to one's children within the non-medical reasons to want IVF-with-ROPA.

Wanting to have a biological connection (either genetic or gestational) to one's children is, I claim, a legitimate wish-but

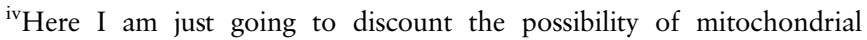
replacement as an alternative to (e) for simplicity's sake.

${ }^{v}$ Here again I am discounting the possibility of mitochondrial replacement. Also, I am not claiming that this is the only difference between ROPA and these other possibilities, just the one I focus on in this paper. Other aspects may include, for example in the case of surrogacy, the fact that many couples would hesitate on surrogacy because they do not want another woman to take on the risk of going through pregnancy, and prefer that they carry the pregnancy themselves - thanks to a referee for this suggestion.
}

only in terms of individual liberty; there is no deeper meaning to it than that, as I will argue below. The language of positive and negative rights may help illustrate this point: wanting to have a biological connection to one's children is legitimate, so the state ought not to interfere with it; but, having no deeper meaning than liberty, the state may not be obliged to support this wish by, say, paying for it.

In the next two sections I offer my argument against the intrinsic value of biological ties, in two steps: first I criticise a recent influential argument by the philosopher J David Velleman for the value of biological ties and then I offer a positive argument for the claim that biological ties, and their redistribution, ought not to be valued.

\section{THE VALUE OF BIOLOGICAL TIES}

Velleman has recently argued that biological ties are meaningful: ${ }^{10}$ indeed, Velleman takes their meaning to be so significant that "people who create children by donor conception already know-or already should know-that their children will be disadvantaged by the lack of a basic good on which most people rely in their pursuit of self-knowledge and identity formation" (ref. 10, pp 364-65). Velleman concludes that the practice of what he calls 'donor conception' is morally wrong and that "other things being equal, children should be raised by their biological parents" (ref. 10, p 362).

Before assessing the merits of Velleman's argument, let me note its peculiar dialectical relationship to our discussion: Velleman's argument can be used to argue in support of IVF-with-ROPA as far as IVF-with-ROPA is a way for both intentional parents to be biologically tied to their children, but it could also be used to argue against IVF-with-ROPA as far as it requires donated sperm by someone outside the parental project. $^{\text {vi }}$ Also, there is an asymmetry between Velleman's argument for the importance of biological ties for the identity of children and our discussion of the importance of biological ties for parents: as we have seen in the distinction between (e1) and (e2), the wish for biological ties may not necessarily be motivated by something related to the future child but may have solely to do with the prospective parents or with their relationship to each other.

Velleman's reasons for thinking that biological ties are meaningful have to do with the role that he assigns to family history for a person's identity. Velleman offers a plausible account of how having some access to one's ancestors is important for self-understanding. What I find less plausible is Velleman's insistence that what is identity-forming isn't just access to one's family history but rather access to a biological history which is identical to one's family history: that he motivates by appeal to "the resemblances that hold within biological families" (ref. 10, p 376).

Whether or not one thinks that such family resemblances are identity-forming or anyhow meaningful, the important point to make against Velleman is that biological families are neither necessary nor sufficient for identity-forming family resemblances. Upbringing may not just be sufficiently identity-forming, but it may be so exactly in virtue of the family resemblances emphasised by Velleman: namely, one's inevitable family resemblances to one's intentional parents and siblings which result from common upbringing, habits, values. At the same time, biological

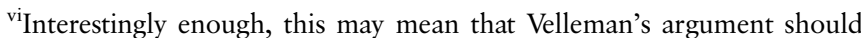
support, in these particular cases, triparenting. ${ }^{11}$ But this point is beyond the scope here.
} 
resemblances may not result in anything significant enough to be identity-forming. Take one of Velleman's own examples: knowing my parents and how my parents have brought me up and knowing their parents and how their parents brought them up may have significant repercussions for how I bring my own children up. One can readily agree with this without any appeal to biological ties.

I must say I am also unmoved by Velleman's appeal to the fact that 'about $50 \%$, 12 of adopted persons will search for their biological parents at some point in their life. First, those numbers aren't very significant, as about 50\% never search for their biological parents either, then. Second, the case of adoption has the peculiarity that it points to a particular event in the person's life (eg, having been abandoned or anyhow having been given up for adoption) and not just to their biological history. Finally, there is the issue of many adopted persons finding out, at some point in their life, that their history is different from the one they had either been told or imagined-and this again may lead to some 'searching' which would not be necessarily motivated by biological considerations. So, again, Velleman may be right that history is important to someone's identity and the adoption data may even point to that (even though it is, in fairness, evenly spilt), but that would again not imply that biological history is particularly important.

Summing up my argument against Velleman, I am sympathetic to his account of how access to one's family history is important for identity and self-knowledge, but I think that the narrative significance of such access does not depend on the family being one's biological family. ${ }^{\text {vii }}$

So far I have only been offering negative arguments by criticising Velleman's claim that biological ties are meaningful. I now want to offer a more substantial argument to the extent that biological ties ought not to be meaningful to the prospective parents. I think it would be morally reproachable for a parent to love their child less should they find out that-for whatever reason-the child was not biologically tied to them. And this applies to genetic parenthood as much as gestation: it is similarly morally reproachable for fathers in traditional contexts to love their children less than their mothers do because they have not gestated them. viii

Here it may be objected that it is similarly both psychologically implausible and morally reproachable for a parent to love their child less should the child lose a leg but that this does quite clearly not imply that the parent ought not to have a preference for a two-legged child in the first place. This is true, but one would hope that the parent's reason to prefer a two-legged child is related to the child's welfare rather than the parent's or her ability to love a one-legged child.

\section{FAIRNESS WITHIN PARENTAL PROJECTS AND BIOLOGICAL TIES}

The following objection could be raised against my argument here: I have only argued that there is no intrinsic value in parents' biological ties to their children; even if my argument is successful in showing that there is no particular value in a parent's wish to be biologically connected to her children, one

\footnotetext{
${ }^{\text {vii }}$ Sally Haslanger offers a more detailed critique of Velleman's arguments in ref. 13 . See also refs. 14 and 15 .

viiishould one worry that 'love' ought not to be used here because it makes the assessment of 'morally reproachable' difficult, one can replace it with, say, a partial commitment to the welfare and fulfillment of the child; I think the same considerations would still apply.
}

may still defend the added value of IVF-with-ROPA on the grounds that it allows for a more equal relationship or parental project in distributing biological ties more equally than, say, a traditional IVF with both eggs and gestation by the same partner (or, for that matter, either surrogacy or egg donation where, at best, again only one partner has biological ties-note that the inclusive nature of the disjunction 'surrogacy $\mathrm{v}$ egg donation' also allows for a scenario where no partner has a biological tie to the child).

As I have mentioned, there is some empirical evidence that these and similar concerns (even jealousy) play a role in some parental projects. $^{67}$ I respect those preoccupations and I am wholeheartedly in favour of more balanced parental projects, ${ }^{16}$ but I think this particular way of striving for more balanced parental projects is self-defeating because I am afraid that worries about inequalities or imbalances within a relationship that are due to differences in the biological ties of the partners to their children are patriarchal in nature, as they are likely mirrored on roles within traditional families where-let us not forget-there are also differences in the biological ties of the partners to their children, as only one partner is the gestational parent.

Our commitment to equality, then, is exactly what should make us sceptical of this appeal to biological ties based on patriarchal prejudices about how biological ties affect role distribution and power imbalances within a family.

A parental project cannot be liberated from the patriarchal norm by trying to redistribute the very phenomenon, biological ties, which is consistently used to reinforce our patriarchal status quo: rather, liberation requires the establishment of fair and equal parental projects where biological ties do not play any role in the distribution of roles, responsibility and, ultimately, power.

We see now that there is a further general consequence relevant to all parental projects arising from our discussion of IVF-with-ROPA, on top of what we have already said about the value of parents' biological ties with their children. The second general element is this: a difference in biological ties within the parental project should not affect the parents' relations with their children nor the parents' own relationship; it should not affect, in short, what we have referred to as the distribution of roles, responsibility and power within the family. To put it very simply: women in traditional contexts ought not to be taking on a greater burden (or even just a greater role) within the parental project simply in virtue of the fact that they have a biological tie to the children (genetics plus gestation) that men in traditional contexts do not have (only genetics).

I have now completed my argument. Summing up, I have argued that there is no added value in IVF-with-ROPA coming from its redistribution of biological ties because, first, there is no intrinsic value in parents' biological ties to their children, and second, because role distribution within parental projects ought to be free from biological considerations. But there is one final worry that I want to briefly deal with: namely that failing to acknowledge the added value of IVF-with-ROPA constitutes a form of discrimination against same-sex couples. But here I have neither argued that there is something morally wrong with IVF-with-ROPA nor have I argued that it ought not to be legal. In fact, I think that IVF-with-ROPA ought to be morally permissible and also legal; and indeed I do fear that countries (such as eg, Sweden) ${ }^{7}$ which allow for traditional IVF but not for IVF-with-ROPA, may be guilty of both incoherence and discrimination towards same-sex couples: this is because they preclude some same-sex couples from satisfying a legitimate wish towards biological ties with their children which is readily available for 
different-sex couples. On the other hand, I do not think that it amounts to discrimination to argue, as I have done here, that IVF-with-ROPA does not constitute added value by virtue of its redistribution of biological ties. ${ }^{\text {ix }}$

\section{CONCLUSION}

IVF-with-ROPA, where within lesbian couples one partner provides the egg while the other becomes pregnant, opens up the possibility of sharing biological ties to children within same-sex couples. Here I have looked at whether biological ties to children in general and their sharing between parents in particular are intrinsically valuable and I have argued that neither is: briefly, family history, as Velleman has argued, may be important to a person's identity and self-knowledge, but its importance is independent from the family being one's biological family. Also, biological ties ought not to play any role in the distribution of burdens and power within parental projects. A final word: we should welcome IVF-with-ROPA because it offers a new possibility to fulfil a very human wish, but we should be careful not to end up thereby reinforcing patriarchal prejudices about the importance of biology.

\footnotetext{
ix Therefore one may argue that the state should, in general, not be paying for whatever extra resources IVF-with-ROPA may require, but I won't pursue this argument here because it would take us too far, as it is not specific to ROPA or even just to IVF; and in any case I am happy to accept that medical IVF-with-ROPA such as in cases (a) and (b) should be publicly funded; I am also willing to allow for the possibility that it would just be too impracticable to distinguish between other IVF treatments and IVF-with-ROPA and that therefore it is just best to treat IVF-with-ROPA just like any other form of IVF treatment (and therefore also that my argument may have consequences for the funding of traditional IVF too): what I am interested in is the point of principle about the value of biological ties.
}

Acknowledgements Many thanks for feedback to audiences in Stockholm, Aarhus, Dublin and Ferrara and also to Laura Emdal Navne and Anna Pichelstorfer.

Competing interests None declared.

Provenance and peer review Not commissioned; externally peer reviewed.

\section{REFERENCES}

1 Marina S, Marina D, Marina F, et al. Sharing motherhood: biological lesbian co-mothers, a new IVF indication. Hum Reprod 2010;25:938-41.

2 Pennings $G$. Having a child together in lesbian families: combining gestation and genetics. J Med Ethics 2016;42:253-5.

3 Machin R. Sharing motherhood in lesbian reproductive practices. Biosocieties 2014;9:42-59.

4 Yeshua A, Lee JA, Witkin G, et al. Female couples undergoing IVF with partner eggs (co-IVF): pathways to parenthood. LGBT Health 2015;2:135-9.

5 Zeiler K, Malmquist A. Lesbian shared biological motherhood: the ethics of IVF with reception of oocytes from partner. Med Health Care Philos 2014;17: 347-55.

6 Pelka S. Sharing motherhood: maternal jealousy among lesbian co-mothers. J Homosex 2009;56:195-217.

7 Rozental A, Malmquist A. Vulnerability and acceptance: lesbian women's family-making through assisted reproduction in Swedish public health care. J GLBT Fam Stud 2015;11:127-50.

8 Padavic I, Butterfield J. Mothers, fathers, and "mathers": negotiating a lesbian co-parental identity. Gender Soc 2011;25:176-96.

9 Pelka S. Third-party reproduction: creating kinship through an intent to parent. Anthropol News 2009;50:8-12.

10 Velleman JD. Family history. Philos Pap 2005;34:357-78.

11 Cutas D. On triparenting. Is having three committed parents better than having only two? J Med Ethics 2011;37:735-8.

12 Müller U, Perry B. Adopted persons' search for and contact with their birth parents I: Who searches and why? Adoption Q 2001;4:5-37.

13 Haslanger $S$. Family, ancestry and self: what is the moral significance of biological ties? Adoption Cult 2009;2.1.

14 Bayne T, Kolers A. Towards a pluralistic account of parenthood. Bioethics 2003;17:221-42.

15 Fuscaldo G. Genetic ties: are they morally binding? Bioethics 2006;20:64-76.

16 Di Nucci E. Fathers and abortion. J Med Philos 2014;39:444-58. 